\title{
Insight to Edifice of Moving Message Boards
}

\author{
Madandola Tajudeen Niyi ${ }^{1}$, Sakariyay Sherif Niyi ${ }^{2}$, Oyelowo Philip Olalekan ${ }^{3}$ \\ ${ }^{1,2}$ Department of Computer Science, Kwara State College of Education, Oro, Nigeria \\ ${ }^{3}$ Department of Physics, Kwara State College of Education, Oro, Nigeria \\ nmadandola@yahoo.com
}

\begin{abstract}
The most significant means of communicating from a computer to an individual is moving message boards also called Text Electronic Display. It is an element of a sign that is capable of displaying words, symbols, figures, or images that electronically or mechanically change by remote or automatic means. It is based on light-emitting diodes and it is connected in an array flat form. It is useful for creating attention-getting messages presentations, advertisements and location identifiers. The 1024 counter enables the information to be displayed sequentially as desire. The driver unit uses transistor to amplify the signal strength of the counter output. The output unit enables the information to be displayed using light emitting diodes (LEDs). Micro-controller AT89C51 provides output to control the logic levels for the sixteen rows of 32 by 16 matrix edifice.
\end{abstract}

Keywords: micro-controller; electronics; edifice; modules

\section{Introduction}

Presently announcement is automated, shopping mall, banks, educational sectors and other agencies displayed their products and services digitally. Moving Message Boards or Text Electronic Displays or alphanumeric displays, or Message electronic display are programmable electronic devices for displaying textual information (Tata, 2004). Text Electronic Display is an electronic gadget capable of displaying length of alphanumeric characters, symbols and any form of representation on a matrix of Light Emitting Diodes (LED) scrolling the characters across the screen for reading the emerging information (Okunola, Oyewale, Idara \& Adebisi, 2019). It is also defined as an element of a sign that is capable of displaying words, symbols, figures, or images that electronically or mechanically change by remote or automatic means (https://www.lawinsider.com/dictionary/electronicmessage-display).

The information can be static and dynamic (moving message). It is a means of getting information across to large or small audiences quickly and efficiently. Information to be displayed are entered by a user from PC through a standard serial bus line (RS232, RS485), network bus Ethernet (TCP/IP) or industrial line Profibus DP or Lon Works. Special application program for preparing, simulating and programming of text messages into display is used. Displays are manufactured on the basis of high-brightness LED elements, which ensure their good displaying properties, high endurance and long lifetime. LED synergy electronic LED display screens are an excellent medium for communication (Tata, 2004).

The Cathode Ray Tube (CRT) which has been the dominant display device used in offices and homes is the display devices on which the personal computer and the graphical user interface were developed (Wisnieff \& Ritsko, 2000). Underlying technology was described as part of the deployment of electronic signage for public transits in Johannesburg, before the 2010 FIFA World Cup (Schweiger, 2013).

\section{Review of Literature}

\subsection{Major Components}

There are several components required but below are major ones: 
i. Modules / Dot matrix (P 10 modules)

ii. Brain box/ Prototype/ Executor

iii. Adapter

iv. Power connector

v. Signal Connector.

\subsection{Modules / Dot Matrix Display}

A Dot Matrix Display as shown in Figure 1 is an electronic digital display device that displays information on machines, clocks and watches, public transport departure indicators and many others devices requiring a simple display device of limited resolution.

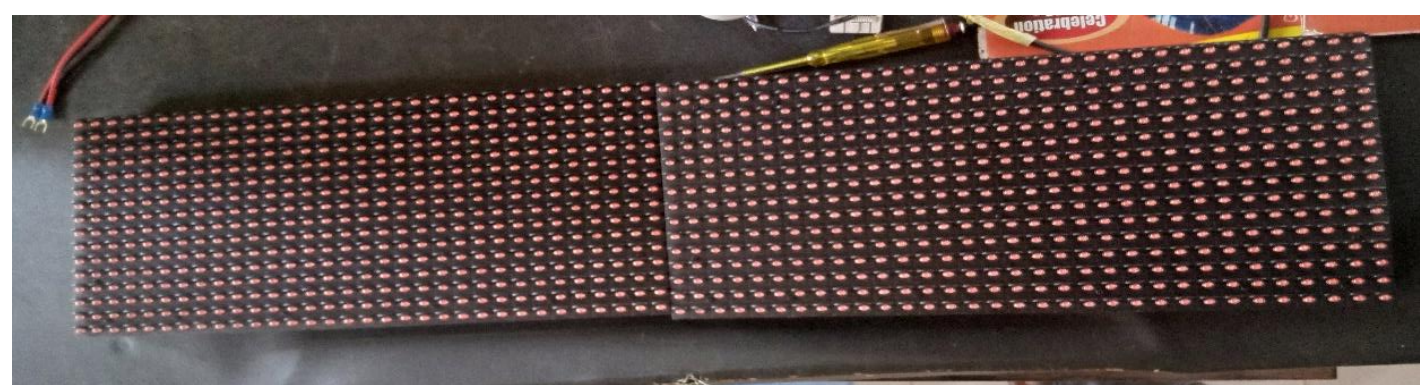

Figure 1. Dot Matrix Display

(Source: field work)

Common size of dot matrix display includes:
1. $32 \times 16$ (one line)
2. $64 \times 16$ (two line)
3. $128 \times 16$ (three lined)
4. $128 \times 32$ (four lined)
5. $128 \times 64$ (eight lined)

Dot Matrix Display comprises of many components which includes the following:

i. CHIPs: the chips are mounted at the back of the modules, and they are about 20. They are connected to the led in order to show and this are control by each line of the led in order to control the text in slant or straight form.

ii. CAPACITOR: they filter and made the voltage constant i.e stable

iii. COLOUR: These modules has different colour such as; RGB (Red, Green, Blue) \& R (Red). The RGB (Red, green and blue) is used in video electronic display while the R (Red) is used in text electronic display.

iv. INPUT AND OUTPUT CONNECTOR: The input and output connector is where the signal connector will be connected into another modules and also to the brain box.

\subsection{Brain Box/ Prototype/ Executor}

A brain box as shown in Figure 2 is the one that is already configured to execute all the task/problem in the gadget.

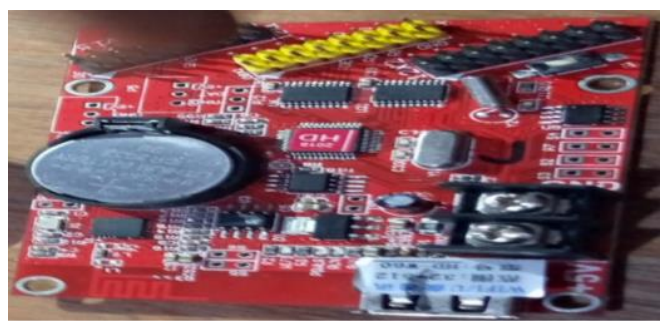

Figure 2. Brain Box

(Source: Field Work) 
Okunola, Oyewale, Idara \& Adebisi, (2019) opined that Brain box comprises of many components which includes the following:

i. Reset Button: it is used to check/test whether anything program is been active on the LED before the program is been uploaded.

ii. Chip: it is used to control the scrolling of the text.

iii. Pin out: this allow us to know the place to socket our module in order to give out information or the result

iv. USB: this is the data out, which is used in video card display to transfer the video or image from one video screen to another.

v. CMOS (complementary metal oxide semi-conductor) Battery: this is used to keep the time constant. The complementary Metal-oxide semiconductor battery is a physical part of the motherboard. It is a memory chip that houses setting configurations and is powered by the onboard battery and also for keeping the time constant.

vi. Crystal oscillator: this is used to collect the signal and without it, the electronic board will not function.

vii. Resistor: The purpose of a resistor is to...resist electricity! Why would we want to do that? To control how much current goes where. One reason is to protect other devices. We will use resistors to control how many current flows through our light-emitting diodes, both to control their brightness and to protect them.

viii. Diode: A diode is a device that allows current to flow in only one direction.

ix. Current can pass in the direction the "arrow" is pointing, that is from the anode to the cathode. The line at the point of the arrow reminds us that current cannot flow in that direction, from cathode to anode. In our case, we will be using light-emitting diodes. When current flows, they light up.

x. Capacitor: A capacitor is a passive two-terminal electronic component that stores electrical energy in an electric field. The effect of a capacitor is known as capacitance.

xi. Transistor: A transistor semiconductor device used to amplify or switch electronic signals and electrical power. It is composed of semiconductor material usually with at least three terminals for connection to an external circuit.

xii. Ground: A ground is the reference point in an electrical circuit from which voltages are measured, a common return path for electric current, or a direct physical connection to the earth.

xiii. Inductor: An inductor is a passive electronic component that stores-energy in the form of a magnetic field. In its simplest form, an inductor consists of a wire loop or coil. The inductance is directly proportional to the number of-turns in the coil.

\subsection{Adaptor/Plug}

Adaptor/Plug as shown in Figure 3 is a $5 \mathrm{~V}$ connector/plug and the plug that is used to connect module to power supply. It must be $5 \mathrm{~V}$ before connecting to the module.

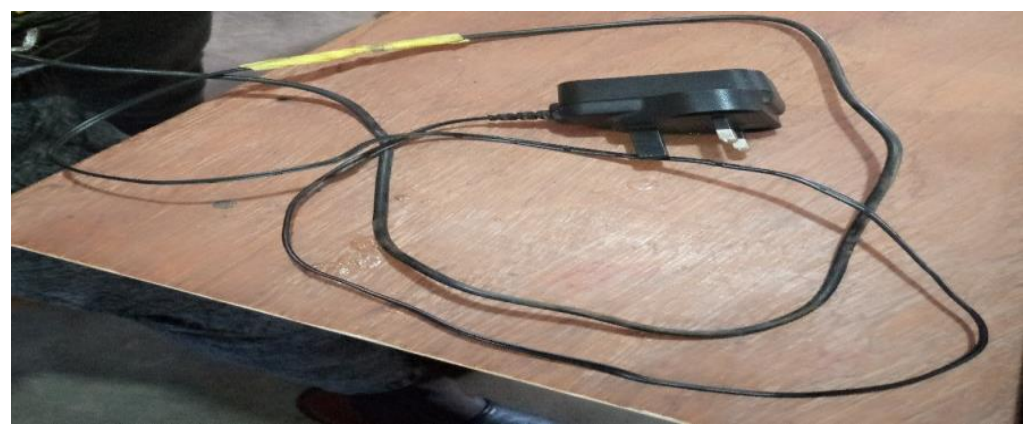

Figure 3. Adaptor

(Source: field work) 


\subsection{Signal Connector}

The cable as shown in Figure 4 is used in connecting the module and the brain box in order to give information from the phone/system to the screen.

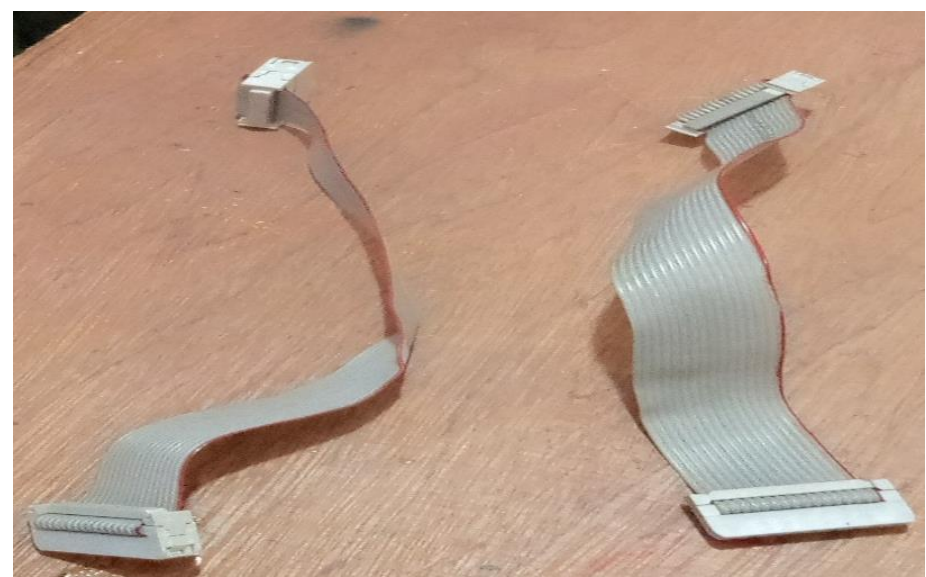

Figure 4. Signal Connector

(Source: Field Work)

\subsection{Power Connector}

Power connector as shown in Figure 5, is a cable indicating the positive and the negative signal (the VCC and GND) Voltage at the common collector and Ground respectively. It is used in powering the two modules and the brain box to function.

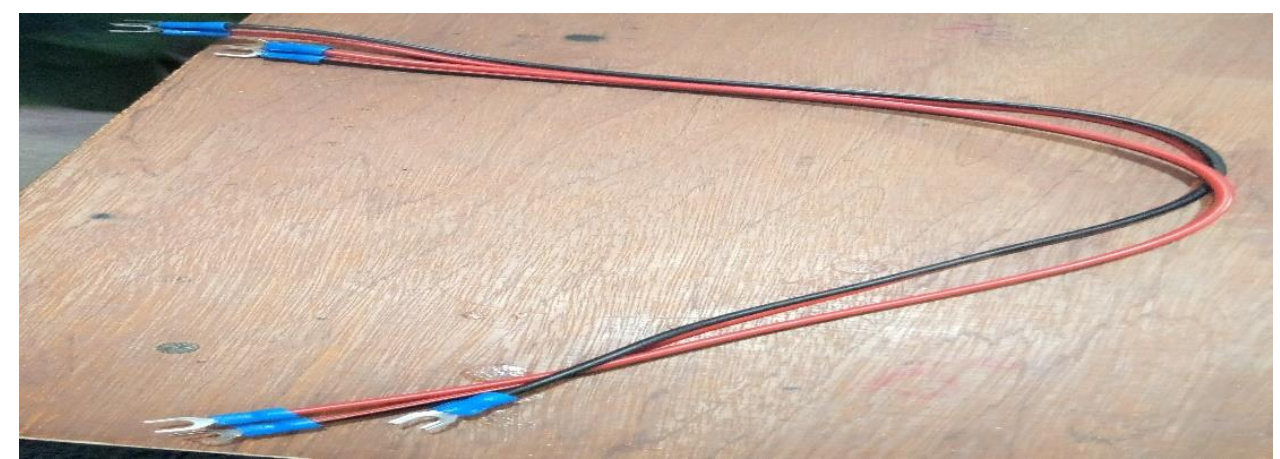

Figure 5. Power Connector

(Source: Field Work)

\section{Discussion}

\subsection{Types of Text Electronic Displays}

There are varieties of Text Electronic Displays, some of the types of the underlying technologies for full-area 2-dimensional displays include:

i. Cathode ray tube display (CRT)

ii. Light-emitting diode display (LED)

iii. Electroluminescent display (ELD)

iv. Electronic paper, E Ink. see Figure 6

v. Plasma display panel (PDP), see Figure 7

vi. Liquid crystal display (LCD)

vii. Organic light-emitting diode display (OLED) 

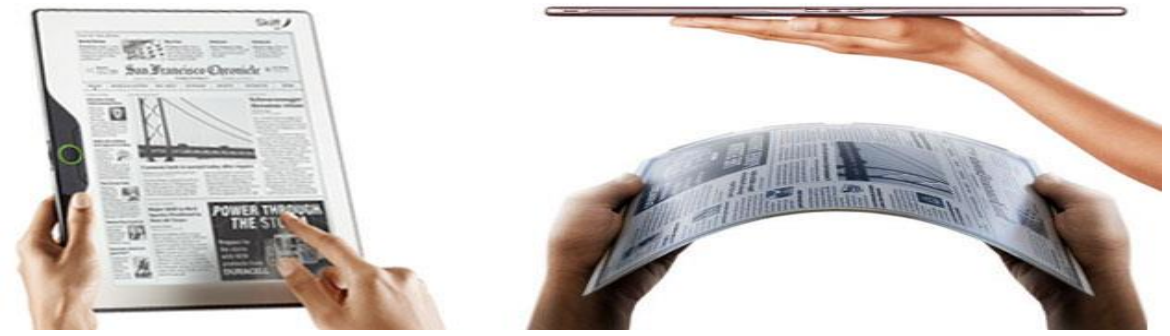

Figure 6. Electronic Paper

(Okunola, Oyewale, Idara and Adebisi, 2019)

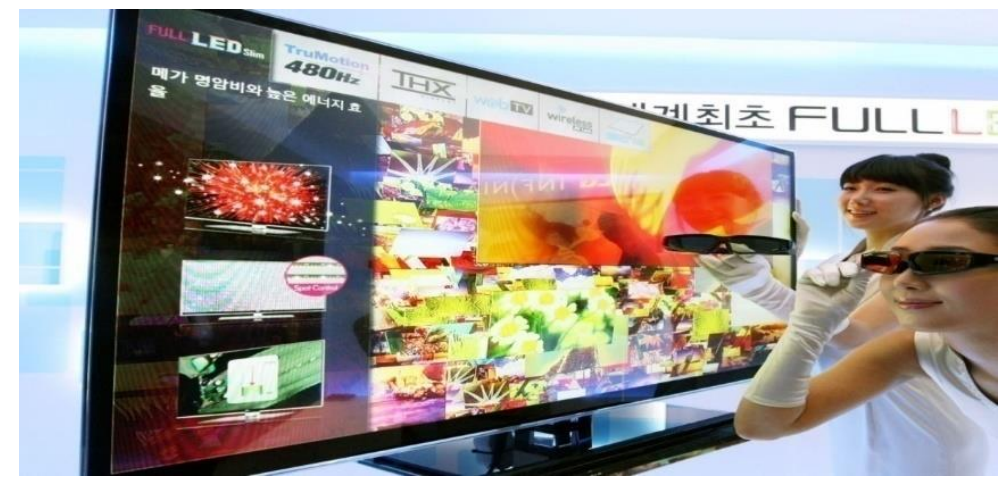

Figure 7. Plasma Display Panel (PDP)

(Okunola, Oyewale, Idara and Adebisi, 2019)

\section{a. Uses of Text Electronic Display}

i. It is used for long readability range as output display devices in electronic format,

ii. It is used as control systems,

iii. It is used as monitoring systems,

iv. It is used as stand-alone boards with advertisement messages.

\section{b. Applications of Text Electronic Display}

The alphanumeric displays can be used in various private, commercial, or industrial applications. Some of the applications which we have realized for our customers in the past includes:

i. Displaying of advertisement messages, indoor or outdoor (shopping centers, stores, etc.);

ii. Displaying special offers for customers (banks and various offices);

iii. Information for hospital patients and doctors;

iv. Showing extraordinary events (Metro Prague, subway);

v. Actual information about traffic; and so on

\section{c. Related Works}

The system is to develop a wireless notice board that parades messages send from the user's mobile. The GSM modem interfaced with level shifter IC to Microcontroller. The message received by the GSM is sent to the microcontroller that further displays it on an electronic noticeboard. The Noticeboard is an LCD display interfaced to a microcontroller, powered by a regulated power supply from main supply of 230-volt AC supply. It must be regulated because sometimes one faces problems with the quality of electrical power in the electrical system (Faisal, Noorly \& Partaonan, 2021). The system accepts the message to be displayed in the form of Short Message Service (SMS), stores it, checks for its validation and then displays it on the display unit if it from an authorized user. It provides only one message 
at a time. This restraint can be solved by use of higher end microcontroller and extended RAM (Krithika, Manju, Mawnash, Mohamed \& Arvind, 2018).

Foram, Anubbhav and Pritish, (2013) presented an SMS based notice board integrating the broadly used GSM to enable the communication of displaying message on notice board via user's mobile phone. Its operation is based on microcontroller ATMEGA32 programmed in assembly language. A SIM300 GSM modem with a SIM card is interfaced to the ports of the microcontroller with the help of AT commands. It was experimented on real time noticing.

In the application of electronic signage for the bus arrival information in bus rapid transit (BRT) stations, an Advanced Public Transport Management System (APTMS) was implemented, consisting of in-vehicle and central fleet managenet systems. These underlying technologies provide next bus information (Tritter \& Bruzon, 2010).

Less advanced underlying technology was used as part of a demonstration of a transport guidance system in a bus terminal in Tsukuba City near Tokyo Japan. The system combines a system which applies (Radio Frequency Identification) technology in wide use in distribution and an LED display type electronic board. It detects a bus leaving the bus terminal and updates the display content (Sakai, Morii, Hirasawa, Kishi, Munehiro \& Sawabe, 2009).

\subsection{Construction and Result of Led Scrolling Display \\ a. Construction}

The construction stage of any project is a critical stage that requires serious attention. The construction of the Text Electronic display system was done in such a way that connection followed the circuit diagram. The LEDs were connected anode to anode and cathode to cathode (series connection) in a 64 by 16 formats so that the system can display 2 or more character at a time, each comprising of 32 by 16 LEDs. Thus each letter is typified with 16 LEDs on the vertical axis and 32 LEDs on the horizontal axis (ONE MODULE).

The connection of LEDs is interfaced with the micro-controller and four line decoders which control the display and movement of messages. The system's internal circuits connected in such a way that every unit except the transformer is mounted on the same circuit board. This was done to minimize the weight of the message display systems. Total number of 1,024 LEDs were used in order to display all the letter at a time. A reddish translucent glass was used in order to make the display visible.

The matrix area is connected in series, the LED is connected to series from end to beginning and beginning to end in series shape. The matrix depends on the board, the modules are two (2) singles 32 by 16, it was castrated out using signal connectors each has different voltage input, the input connected to the controller must be corresponds with the one on the modules the voltage supply was not less than $5 \mathrm{~V}$ because it is a digital board.

\section{b. Requirements for Implementation}

- Without the software, modules cannot run successfully, we can make use of computer or phone but computer is more preferable because it has more functions than the phone, for example setting to change messages.

- "Wi-fi" deals with internet but this does not deal with or data, it does not require recharging of line or subscription.

- The chips control gets the message from the computer and displayed it as a message on the modules.

- Source of power supply. It can be Electricity, Solar-inverter or any source. Note that; low efficiency of the inverter used can shorten the life of the equipment (Noorly, Faisal \& Abdul Azis, 2021) 


\section{Steps 1:}

On the computer /Phone, under tools we have module setup which required a password, we inserted the password.

\section{Steps 2:}

We have control setup which also required a password and the password was inserted as well, without the password we cannot go further or allowed to write any characters.

\section{Step 3:}

We go to the selection page, under selection page we have, Speed, Edge, Hold, Rotational, $3 \mathrm{D}$, Fly to right, left to but animation text right, swing etc.

\section{Step 4:}

We click on send.

\subsection{Samples of the Output from the Construction \\ Program 1:}

The character "Madandola" was inputted, then we click on the size, then the speed etc and then we click on send and it displayed the message on the modules as displayed in Figure 8.

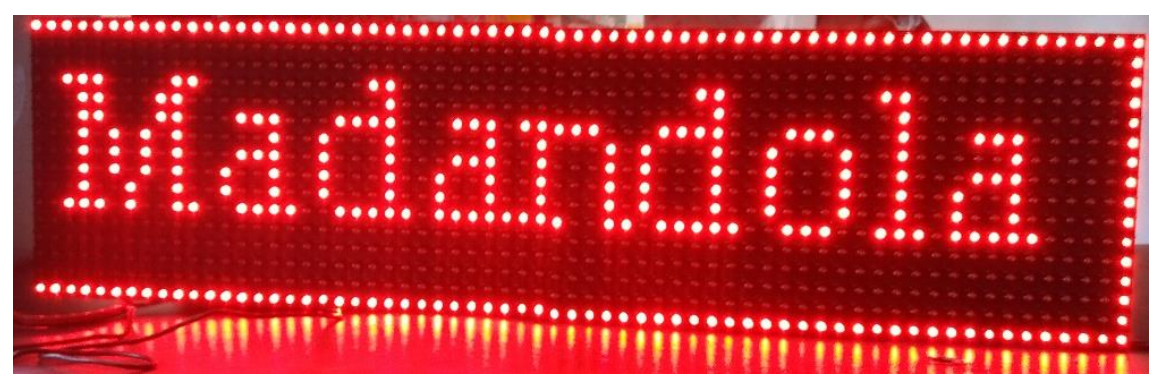

Figure 8. One-word Output Result that is "Madandola"

The software is modified for displaying a text of one word 9 characters

\section{Program 2:}

The character "Computer Science Department, Kwara State College of Education, Oro" was also inputted, then we click on the size, then the speed etc and then we click on send and it displayed the message on the modules as displayed in Figure 9.

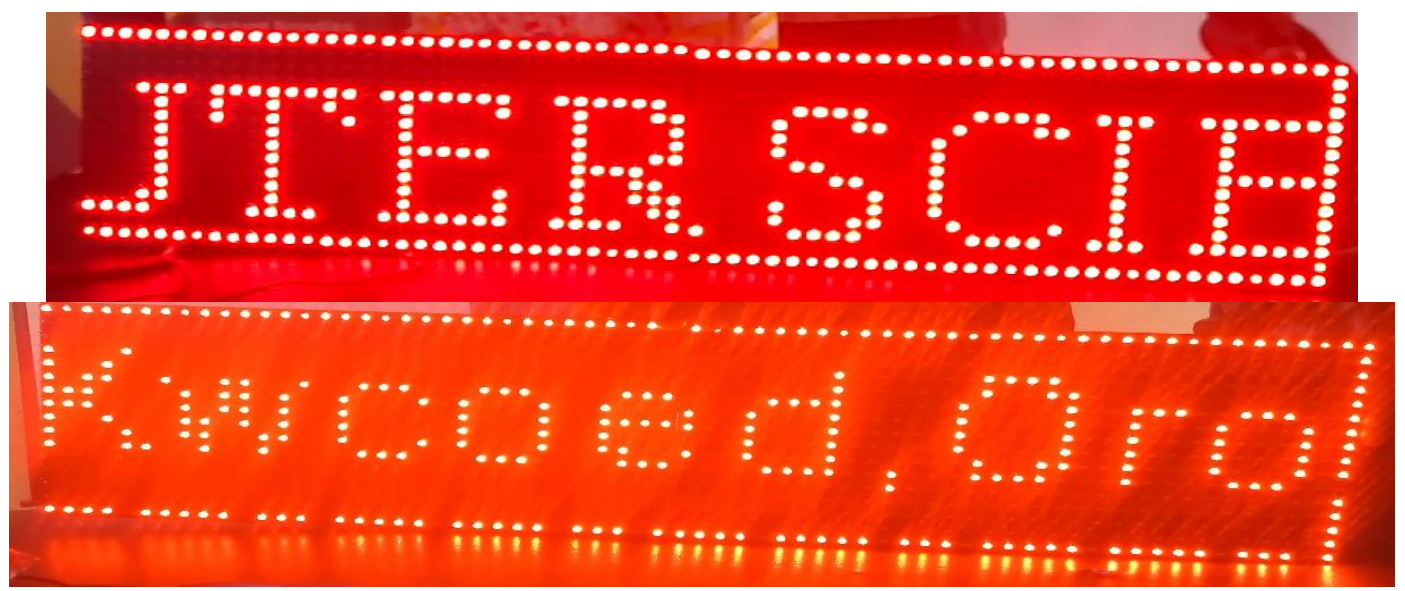

Figure 9. Display Text with Spacing between Character (One Column of) and a Complete off Module between Nine Words

Program 3: The character "Date" which is "14.11.2020", was inputted, then we click on the size, then the speed e.t.c and then we click on send and it displayed the message on the modules as displayed in Figure 10. 


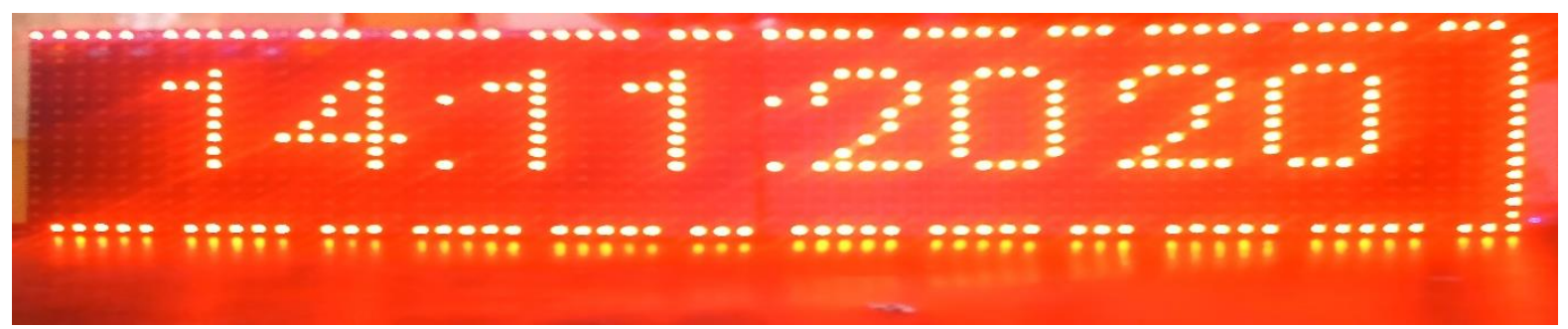

Figure 10. Displayed Text in Numeral which is "date: 14.11.2020

Program 4: The character "Time" which is "19:53:40", was inputted, then we click on the size, then the speed etc and then we click on send and it displayed the message on the modules as displayed in Figure 11.

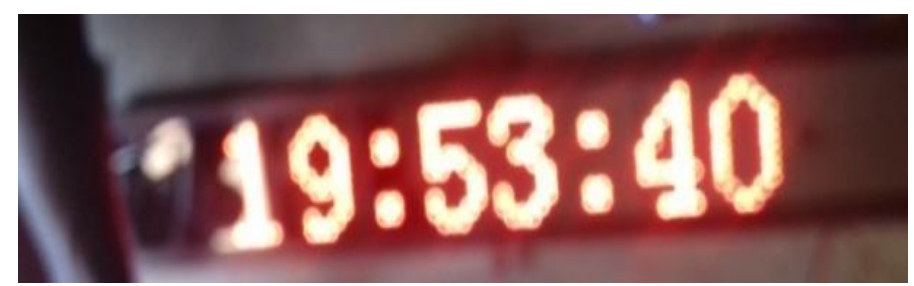

Figure 11. Displayed the Text of Time in Numeral (19:53:40)

\section{Conclusion}

\subsection{Conclusion}

The Text Electronic Display has been modernized with sophisticated electronic devices, which centre on the urgent needs in our advertising industry. They provide various application in different aspects of our economy such as Banks, Airport, Restaurants, Superstores, Institutions, Entertainment, Stock Exchange, Market and Directional venue guides.

The light emitting diode which constitute of the hardware system is mainly used to display alphanumeric characters and symbols in various systems such as digital clocks, microwaves oven, stereo tuners and calculators. The construction of running message display system have a single micro-controller chip.

\subsection{Recommendations}

Text Electronic Display is highly recommended because:

i. It aids advertisement in the marketing economy

ii. In educational sector if adopted it will assist in displaying information especially students result instead of pasting message/results on the wall

iii. The technology behind its production is not cumbersome therefore young leavers can venture into it as source of generating income

ii. It will promote security and reduce crime rate

\section{References}

Evalina, N., Pasaribu, F.I and Azis, A.H. (2021). The Use of Inverters in Solar Power Plants for Alternating Current Loads. Britain International of Exact Sciences Journal, 3(3). DOI: https://doi.org/10.33258/bioex.v3i3.496

Foram, Kamdar; Anubbhav, Malhotra and Pritish, Mahadik (2013). Display Message on Notice Board using GSM. Advance in Electronic and Electric Engineering India Publications. ISSN 2231-1297, 3(7): 827-832

https://www.lawinsider.com/dictionary/electronic-message-display 
Krithika, S., Manju U, Mawnash E K, Mohamed Y. A. and Arvind, C. (2018). WIRELESS NOTICE BOARD USING GSM. International Journal of Pure and Applied Mathematics. 118(20), 633-636 ISSN: 1311-8080 (printed version)

Okunola, A. O., Oyewale, A. S., Idara, W. and Adebisi, Fatai (2019). Construction of electronic digital display system. Department of Electrical /Electromics Engineering Department, Federal Polytechnic, Offa, Kwara State. Unpublished project.

Pasaribu, F.I., Evalina, N., and Harahap, P. (2021). Varistor in the Inverator Circuit Starting Energy Saver to Reduce Water Pump Electric Current. Budapest International Research in Exact Sciences (BirEx Journal). 3(4).

Sakai, K., Morii, K.N., Hirasawa T., Kishi, K., Munehiro, Y. and Sawabe, S. (2009). A StepBy-Step Procedure to Introduce Low-Cost Transport Guidance Systems Using ICT at Bus Terminal. Proceedings of the 16th World Congress on ITS. Stockholm, Sweden p.7.

Schweiger, C. (2013). Use of Electronic Passenger Information Signage in Transit (2013). The National Academies of Sciences, Engineering, and Medicine. 500 Fifth St., NW | Washington, DC 20001

Tata, McGraw-Hill, T. (2004). Digital Electronic Principles and Applicatoons (6th ed).

Tritter, B and Bruzon, V. (2010). ITS Deployment in Johannesburg. Proceedings of the 17th Word Congress on ITS. Busan, Korea.

Wisnieff, R. F., \& Ritsko, J. (2000). Electronic Display Information Technology. International Business Machines Journal of Research and Development, 44 (3). 